Vol.45, Special n. : pp. 91-96, September 2002

ISSN 1516-8913 Printed in Brazil

\title{
Radiopeptides from Diagnosis to Therapy
}

\author{
John. R. Buscombe* \\ Department of Nuclear Medicine; Royal Free Hospital; Pond Street; NW3 2QG; London - UK; buscombe@rfhsm.ac.uk
}

\begin{abstract}
Radiopeptides are playing an increasing role in the diagnosis of disease. Initially based on the somatatostatin system, early research concentrated on identifying tumours of neuroendocrine origin. New techniques with artificial peptides are extending their role into other areas such as thrombus formation and heart disease. It has been shown that radiopeptides have excellent labelling new methods have looked at therapy starting with high activities of In111 pentetreotide to the development of Y-90 based products and new and novel peptides and radio isotopes. Outside of PET there are the most exciting developments in nuclear medicine.
\end{abstract}

Key words: Radiopeptides, diagnosis, therapy

\section{INTRODUCTION}

Radiopeptides have been developed primarily for diagnosis. The first such peptide was developed by Mallinckrodt using a version of octreotide with a phenylalanine substitution with would allow a DTPA chelator. This was labelled with In-111 and as In-111 pentetreotide it has become widely used in the diagnosis of a variety of neuroendocrine tumours (Bakker et al, 1991; Kwekkeboom et al., 1993; Krenning et al, 1993). The method delivers high sensitivity in carcinoid for example nearly $90 \%$ of all tumours are seen (Bakker et. al, 1991). The non-visualisation of any particular tumour may not be that it is too small to be resolved using gama camera technology, it may just be that that particular tumour does not express the required somatostatin receptor. The somatostatin system is the main system that has been developed for the use of peptides. The sub receptor type 2 (SSR2) is widely found in many tumour types including medullary cell cancer of the thyroid, small cell lung cancer and lymphoma. Unfortunately it is not tumour specific and biding to $\mathrm{T}$ lymphocytes have been noted (Ferone et al., 2001). It is not surprising then that the somatostatin receptor system was also the first exploited for the use of radiopeptides in therapy. This was initially with high activities of In-111 pentetreotide and later with ytrrium-90 (Y-90) based peptides. First results are encouraging but at present these products are not the magic bullet long hoped for but they have provided evidence that in some patients radiopeptide therapy can be successful. The latest moves have been to develop new peptides with better targeting that will be able to attack tumours better and with lower toxicity. This is the direction in which research into this area is now concentrated.

\footnotetext{
${ }^{*}$ Author for correspondence
} 


\section{CONVERTING EXISTING PEPTIDES}

The simplest method to develop a radiopeptide system is to convert an existing product such as ocreotide an octo-peptide with high affinity for somatostain receptor sub type 2 (SSR2). The use of In-111 DTPA-Phe-octreotide (In-111 pentetreotide) has shown that such a system is robust and can be commercially successful. The main characteristics of this product is swift uptake into the tumour with a high tumour to background ratio (de Jong et al, 2002). The uptake of the peptide may be within a few minutes of the injection of the tracer. The second is retention within the tumour. Little washout is seen even at 48 hours from the tumour with this product. This means that clear imaging and tomography is possible for 48 hours post injection. It is now known that this high uptake and retention is in part due to uptake of the In-111 pentretreotide into the nucleus of the cell and not just the cell cytoplasm (Hofland et al., 1999). The somatostatin system is also widely expressed throughout the body and certain organs have high activity of injected In-111 pentetreotide, including the kidneys, the spleen and the liver. Lower but normal levels of activity are seen in the colon at 24-48 hours and the thyroid. Any other site of uptake is abnormal. The over expression of the receptor was thought to primary occur within the family of neuroendocrine tumours but more recently has been seen in a wide range of tumours. In fact most tumour types to some extent have over expression of SSR2 and may be seen. Benign processes involving lymphocytes may also have uptake, so that "false positive uptake" in sites of infection and inflammatory disease such as sarcoid have been noted (Slavin et al., 1998; Vanhagen et al., 1994). Another area of concern is how is it possible to find sites of tumour which exist in sites of physiological uptake.

\section{IDENTIFYING LIVER DISEASE}

Most disseminated neuroendocrine tumours will contain either metastases in the liver or in surrounding tissues. In our experience neither triple phase CT and MRI may not be able to find these lesions. They may be very small and as they are slow growing have a similar density and MR signal to normal liver. In addition previous surgery and embolisation may make identification of tumour difficult. Functional techniques which do not rely on the anatomy of an organ are therefore at an advantage. Despite these advantages, there may yet be problems finding tumour. This can be solved by the use of tomography normally at 24 and 48 hours post injection when background activity has cleared. Tomography allows overlying structures to be identified and improved contrast resolution (i. e. the contrast between disease and normality). Using tomography it has been possible to find liver metastases in double the number of patients who are positive on CT alone (Ramage et al., 1996). There has been some concern that the co-administration of octreotide therapeutically may interfere with the binding of the radiolabelled product, however in reality this is rarely a problem (Caplin et al., 2000). Once liver disease can be identified it is often useful to use In-111 octreotide to monitor the progress of disease or the effect of any treatment.

\section{OTHER PEPTIDES}

Octreotide is not the only peptide which can be used to image SSR expressing tumours, both vapreotide and lanreotide have been used. The last of these when labelled with In-111 shows a very similar pattern of uptake to In-111 but with some surprising differences (Virgolini et al, 2002). For example whilst nearly $90 \%$ of carcinoid tumours have uptake of In-111 pentetreotide, only $66 \%$ of these tumours have uptake of In-111 lanreotide. However in many cancers such as thyroid, lung or in lymphoma In-111 lanreotide has a higher sensitivity, this is thought in part to be due to the affinity for In-111 lanreotide for both the SSR2 and SSR5 (the latter of these may have a higher expression in cancers than carcinoids).

\section{GASTRIN BASED PRODUCTS}

The gastrin/cholecystokinin-B (CCK-B) system is often found in tumours which ex press somatostatin receptors and in addition a set of gastrointestinal cancers which are negative for SSR 2 and 5. these include gastric and pancreatic cancer as well gallbladder cancer and hepatomas. Unlike somatostain which has a single natural form thes e peptides exist as a family of peptides with a 
common Trp-Met-Asp-Phe N terminal (Behr et al, 2002). All of these will have different binding profiles and may have different pharmacological actions, as unlike the somatostatins all of these appear to have a biological effect at low dose, which may limit their development.

Early work has shown a normal distribution similar to In-111 pentetreotide but with more diffuse lung and focal gastric activity (Behr et al, 2002). Also tumour uptake is less intense, this may be related to the fact that as these peptides are quite short the addition of the linker chelate and the radioisotope may affect receptor binding and affinity. At present there are increasing efforts to develop new gastrin based products which will have high binding affinity and residence but also radio-chemical stability. Thus allowing this agent to be used for therapy.

\section{ARTIFICIAL PETIDES}

The third approach is to build new peptides from their amino acid bases and using the knowledge of the molecular base of the peptide and modelling of the receptor site it may be possible to modify any peptide to increase or decrease receptor affinity and residence. It may be possible to engineer a peptide which has a different profile of normal distribution. For example it may be possible to reduce renal uptake.

The group most advanced in this process id the Diatide company of the USA. So far they have brought 2 products to the market. The first is defined as P280 It is sold as "Accutect" and is not a tumour imaging agent but can be used to find acute thrombus as it has affinity for the IIb/IIIa redceptor on activated platelets (Taillefer et al., 2000). The second is P829, sold as Neotect or Neospect. This is a more traditional tumour imaging agent and like In-111 lanreotide has a higher affinity for SSR5 than In-111 pentetreotide. Unlike In-111 pentetreotide it has high normal bowel physiological activity and so it used mainly in the chest to identify non-small cell lung cancer where it has an accuracy close to F-18 FDG PET (Menda et al., 2002). A whole range of new and exciting peptides are now under development and at least 30 of these were found by Signore et al during a recent review (Signore et al., 2002) . A whole range of pathologies will also be encompassed such as heart and brain disease.

\section{PEPTIDES FOR THERAPY}

To image a tumour is fine but the "holy grail" of targeting is to treat. For 30 years much resources have been directed to antibodies. These however have proved to be expensive with only one produc $t$ Y-90 zevalin and anti-CD20 antibody making FDA approval for general use in this time (Gordon et al., 2002). Antibodies are too expensive to make and too slow to develop a new approach is needed. In-111 pentetreotide was the first. It was noted that it had high affinity for the tumour with little uptake outside of the tumour. This would the way forward in targeted therapy.

\section{In-111 PENTETREOTIDE}

Clearly normal diagnostic activities of In-111 pentetreotide would not have an effect however if higher activities of 3-7 GBq could be used there may be a therapeutic effect from the resulting Auger electrons. These have a range of about $20 \mathrm{~nm}$, but release intense radiation over that range. It is known that in tumour cells the In-111 is localised into the nucleus so a good therapeutic effect could be expected.

Early trials from the Netherlands suggested that there may be a response in about $60 \%$ of patients (de Jong et al., 2002), in our group 16 patients we had a response rate closer to $50 \%$ but this response was sustained for up to 18 months without need for further treatment (Buscombe et al., 2002) Similar results from Louisiana, USA have shown response rates close to $60 \%$ with a good sustained response without further treatment for 18 months after the last treatment was given (Anthony et al., 1997). What was surprising was that there was no renal toxicity. It had been expected to encounter renal toxicity when the radiation dose to the kidney exceeded 29 cGy. However we have calculated that many of our patients have $r$ eceived up to 3 times that level with no toxicity (Caplin et al., 2000). Therefore not all radiation is the same and clearly the use of these radiotargeted products may make us change how we calculate organ doses. 


\section{Y-90 LABELLED PEPTIDES}

The next step to increase cancer kill rates is to substitute In-111 with a beta emitter. The closest in terms of chemical reaction is Y -90. Though not identical the chemistry is close enough to allow labelling of a peptide chain by use of DOTA (de Jong et al., 1997). Unlike DTPA there is an additional chelation site which holds that Y -90 fast, ensuring good stability of label. Y -90 itself is a pure beta emitter and therefore is easier to handle within the clinic as the patient does not need isolation. However the beta is very energetic and care must be taken to ensure that there is optimal uptake in the tumour and less normal tissue caught in the "cross fire" near sites of isotope deposition.

To improve affinity for the receptors Krenning's group have used an octreotide chain where phenylalanine residue is replaced by tyrosine. This product named octreotate may have a slightly higher binding affinity for SSR2. Despite this almost all the clinical work has been based on Y 90 octreotide. Phase 1 dosing and dose escalation studies have been performed and though this was not a primary aim of this study about $40 \%$ of patients showed some response (Chinol et al, 2002). Normal activities are $3-4 \mathrm{GBq}$ at 6 weekly intervals. There is some evidence that this treatment is better for secreting neuroendocrine tumours such as classical carcinoid and insulinoma and for liver metastases.

\section{TOXICITY}

As a dose ranging study it was possible to determine that some toxicity was seen in cumulative activities of between 13 and $16 \mathrm{GBq}$, though some patients have received more than this without problems. The dose limiting organ is the kidney (Chinol et al., 2002), and nephrotoxicity has been seen about 12 months post treatment in a number of patients. Normally this is treated with Captopril, but one patient required dialysis. It has been demonstrated that the binding of the Y-90 octreotide to the proximal tubule of the nephron is inhibited by anionic amino acids. Therefore renal activity of the Y -90 octreotide but be seriously reduced by the coadministration of 15-20 grams of lysine and $10 \mathrm{~g}$ of arginine. Unfortunately this can cause severe nausea and vomiting resistant to most drugs including odansetron. Over $80 \%$ of all patients receiving amino acids will have nausea and vomiting. However there is clear evidence that this does substantially reduce (by about $75 \%$ the renal radiation dose).

Other toxicity include short term grade 1 and 2 haematological toxicity normally platelets with a nadir at 4 weeks and recovery at 6 weeks (Chinol et al, 2002). Minor testicular toxicity has also been seen, but many of these patients have received chemotherapy before their treatment and may be sterile. If this is of concern sperm can be banked before the Y-90 octreotide is given

\section{Y-90 LANREOTIDE}

An alternative to protecting the kidneys with amino acids is to design a different peptide which has minimal renal activity. It has been shown that lanreotide, an alternative somatostatin analogue still has good SSR2. There is little evidence using imaging that neither In-111 and Y-90 lanreotide have significant renal activity. In the Mauritius multi-centre trial (Virgolini et al., 2002) 3-4 x IGBq Y-90 lanreotide was given with up to 2 sessions of treatment. Though it was not thought to be as efficacious as the Y -90 octreotide a similar response rate of $40 \%$ was obtained. The best results were obtained in astrocytomas, thyroid cancer and carcinoids were the response rate was nearly $60 \%$, the worst response rates were in meningiomas and small cell lung cancers, but even here a $30 \%$ response rate was obtained. This is quite remarkable in view of the generally dismal outcome of this tumour. In our group we also noted that liver and brain disease responded better than bone or lymph node metastases.

There was minimal toxicity though about $20 \%$ of patients had mild grade I/II haematological toxicity involving platelets all self reversible. There has been no renal problems but $70 \%$ of patients complained of tiredness after the treatment

\section{INCREASING EFFICACY}

To increase the efficacy of the Y-90 lanreotide in liver and brain disease it may be possible to infuse the product into the artery feeding the tumour. If the first pass extraction is high enough good 
radiation doses can be obtained in the organ involved, but systemic effects are mini mised. In an initial series of 7 patients with brain cancers and 6 with neuroendocrine tumours in the liver the response rate has increased from $40 \%$ partial response and disease stability to $>60$ with partial or complete responses (Buscombe et al, 2002). This method combining pharmacological and physical targeting looks like it may be successful, but at present is limited to organs in which infusional therapy is easy.

\section{CONCLUSION}

This is an exciting time for nuclear medicine, new peptides are being developed which will enable up to see and follow disease processes with new precision. Newer products will enable not just to see a disease but also plan the best way to treat it.

\section{RESUMO}

Radiopeptídeos estão desempenhando um papel cada vez mais relevante no diagnóstico de doenças. Inicialmente dedicado ao sistema somatostatinérgico, a pesquisa nesta área concentrava-se em identificar tumores de origem neuroendócrina. Novas técnicas com peptídeos artificiais estão estendendo seu papel em outras áreas, tais como a formação de trombos em doenças cardíacas. Tem sido mostrado novos e excelentes métodos de marcação de radiopeptídeos começando por aqueles com alta atividade, tais como In-111 pentetreotídeo, ao desenvolvimento de produtos com Y -90 e recentes peptídeos e radioisótopos. Além do PET, há interessantes desenvolvimentos em Medicina Nuclear.

\section{REFERENCES}

Anthony, L. B.; Woltering, E. A.; Espenan, G. D.; Cronin, M. D.; Maloney, T. J. and McCarthy, K. E. (2002), Indium-111-pentetreotide prolongs survival in gastroenteropancreatic malignancies. Semin. Nucl. Med., 32, 123-132.
Bakker, W. H.; Krenning, E. P.; Breeman, W. A.; Kooij, P. P.; Reubi, J. C.; Koper, J. W.; de Jong, M.; Lameris, J. S.; Visser, T. J. and Lamberts, S.W. (1991), In vivo use of a radioiodinated somatostatin analogue: dynamics, metabolism, and binding tosomatostatin receptor-positive tumors in man. J. Nucl. Med., 32, 1184-1189.

Behr, T. M. and Behe, M. P. (2002), Cholecystokinin$\mathrm{B} /$ Gastrin receptor-targeting peptides for staging and therapy of medullary thyroid cancer and other cholecystokinin-B receptor-expressing malignancies. Semin. Nucl. Med., 32, 97-109.

Buscombe, J. R.; Caplin, M. E. and Hilson, A. J. W. (2001), Long term efficacy of In-111 pentetreotide therapy. J. Nucl. Med. [in press].

Buscombe, J. R.; Caplin, M. E.; Pigott, K.; Watkinson, A. J.; Tibbals, J.; Savy, L.; Platts, A.; Valentine, A.; Virgolini, I. and Hilson, A. J.W. (2002), Physical and pharmacological targeting: Hitting neuroendocrine tumours with a "double whammy" use of Y-90 lanreotide given intra-arteriorly J. Nucl. Med., 43, 316.

Caplin, M. E.; Mielcarek, W.; Buscombe, J.R.; Jones, A. L.; Croasdale, P. L.; Cooper, M. S.; Burroughs, A. K. and Hilson, A. J. W. (2000), Toxicity of highactivity $111 \mathrm{In}$-Octreotide therapy in patients with disseminated neuroendocrine tumours. Nucl. Med. Commun., 21, 97-102.

Chinol, M.; Bodei, L.; Cremonesi, M. and Paganelli, G. (2002), Receptor-mediated radiotherapy with YDOTA-DPhe-Tyr-octreotide: the experience of the European Institute of Oncology Group. Semin. Nucl. Med., 32, 141-147.

de Jong, M.; Bakker, W. H.; Krenning, E. P.; Breeman, W. A.; van der Pluijm, M. E.; Bernard, B.F.; Visser, T. J.; Jermann, E.; Behe, M.; Powell, P. and Macke, H. R. (1997), Yttrium-90 and indium-111 labelling, receptor binding and biodistribution of [DOTA0,dPhe1,Tyr3] octreotide, a promising somatostatin analogue for radionuclide therapy. Eur. J. Nucl. Med., 24, 368-371.

de Jong, M. and Krenning, E. (2002), New advances in peptide receptor radionuclide therapy. J. Nucl. Med., 43, 617-620.

De Jong, M.; Valkema, R.; Jamar, F.; Kvols, L. K.; Kwekkeboom, D. J.; Breeman, W. A.; Bakker, W. H.; Smith, C.; Pauwels, S. and Krenning, E. P. (2002), Somatostatin receptor-targeted radionuclide therapy of tumors: preclinical and clinical findings. Semin. Nucl. Med., 32, 133-140.

Ferone, D.; Hofland, L. J.; Colao, A.; Lamberts, S. W. and van Hagen, P. M. (2001), Neuroendocrine aspects of immunolymphoproliferative diseases. Ann. Oncol., 12 : (Suppl 2), S125-130. 
Gordon, L. I.; Witzig, T. E.; Wiseman, G. A.; Flinn, I. W.; Spies, S. S.; Silverman, D. H.; Emmanuolides, C.; Cripe, L.; Saleh, M.; Czuczman, M. S.; Olejnik, T.; White, C. A. and Grillo-Lopez, A. J. (2002), Yttrium 90 ibritumomab tiuxetan radioimmunotherapy for relapsed or refractory lowgrade non-Hodgkin's lymphoma. Semin. Oncol., 29, 87-92.

Hofland, L. J.; Breeman, W. A.; Krenning, E. P.; de Jong, M.; Waaijers, M.; van Koetsveld, P. M.; Macke, H. R. and Lamberts, S. W. (1999), Internalization of [DOTA degrees, 125ITyr3]Octreotide by somatostatin receptor-positive cells in vitro and in vivo: implications for somatostatin receptor-targeted radio-guided surgery. Proc. Assoc. Am. Physicians., 111, 63-69.

Krenning, E. P.; Kwekkeboom, D. J.; Reubi, J. C.; van Hagen, P. M.; van Eijck, C. H.; Oei, H. Y. and Lamberts, S. W. (1993), ${ }^{111}$ In-octreotide scintigraphy in oncology. Digestion., 54 : (Suppl 1), 84-87.

Kwekkeboom, D. J.; Krenning, E. P.; Bakker, W. H.; Oei, H. Y.; Kooij, P. P. and Lamberts, S. W. (1993), Somatostatin analogue scintigraphy in carcinoid tumours. Eur. J. Nucl. Med., 20, 283-293.

Menda, Y. and Kahn, D. (2002), Somatostatin receptor imaging of non-small cell lung cancer with $99 \mathrm{mTc}$ depreotide. Semin. Nucl. Med., 32, 92-96.

Ramage, J. K.; Williams, R. and Buxton-Thomas, M. (1996), Imaging secondary neuroendocrine tumours of the liver: comparison of $\mathrm{I123}$ metaiodobenzylguanidine (MIBG) and In111-labelled octreotide (Octreoscan).Q. J. M., 89, 539-452.
Signore, A.; Annovazzi, A.; Chianelli, M.; Corsetti, F.; Van de Wiele, C. and Watherhouse, R. N. (2001), Peptide radiopharmaceuticals for diagnosis and therapy. Eur. J. Nucl. Med., 28, 1555-1565.

Slavin Jr., J. D.; Sherigar, R. M.; Spencer, R. P. and Lassman, M. N. (1998), In-111 octreotide lung uptake in hypersensitive pneumonitis caused by fungal infection. Clin. Nucl. Med., 23, 847-848.

Taillefer, R.; Edell, S.; Innes, G. and Lister-James, J. (2000), Acute thromboscintigraphy with (99m)Tcapcitide: results of the phase 3 multicenter clinical trial comparing $99 \mathrm{mTc}$-apcitide scintigraphy with contrast venography for imaging acute DVT. Multicenter Trial Investigators. J. Nucl. Med.,41, 1214-1223.

Vanhagen, P. M.; Krenning, E. P.; Reubi, J. C.; Kwekkeboom, D. J.; Bakker, W. H.; Mulder, A. H.; Laissue, I.; Hoogstede, H. C. and Lamberts, S. W. (1994), Somatostatin analogue scintigraphy in granulomatous diseases. Eur. J. Nucl. Med., 21, 497-502.

Virgolini, I.; Britton, K.; Buscombe, J.; Moncayo, R.; Paganelli, G. and Riva, P. (2002), In- Y-DOTAlanreotide: results and implications of the MAURITIUS trial. Semin. Nucl. Med., 32, 148-155.

Received: July 09, 2002; Revised: July 11, 2002; Accepted: July 12, 2002. 